\title{
Specification A Model for Study of Harassment Agenda
}

\author{
Cruz Garcia Lirios* \\ Professor Investigator Universidad de Sonora, Mexico
}

*Corresponding author: Red Transdisciplinar, Professor Investigator Universidad de Sonora, Mexico.

\begin{abstract}
The review and discussion of Internet harassment was the objective of this work. A documentary study was carried out with an intentional selection of sources indexed to repositories such as Dialnet, Latindex, Publindex, Redalyc and Scielo, considering the period from 2010 to 2019 , as well as the key words. A model was specified that included the variables reviewed in the literature, but the design of the research limited the consultation, the debate and the composition of the model, suggesting the inclusion of other variables that the literature identifies as inherent to violence among Internet users.
\end{abstract}

Keywords: Stalking; Trolling; Stashing; Sexting bullying

\section{Introduction}

A review of the literature regarding the study of Internet harassment alludes to variables such as; stalking, stashing, trolling, sexting and bullying. Each one explains the origin, development and consolidation of asymmetric relationships that are not necessarily related to other economic, political, social, cultural or educational differences, but being cross-cutting they increase the gap between victims, stalkers, spectators and promoters [1]. In this way, a review and discussion is necessary to highlight their relationships and guide their composition towards the exploration, explanation and prediction of the behavior of the actors involved in harassment through electronic technologies, devices and networks [2]. However, the literature consulted has focused on the relationship between perpetrators and victims without considering the mediating or moderating role of viewers, promoters or apologists for Internet harassment [3].

In the hegemonic analysis of the differences between bullies and victims, preponderant indicators have been found: bullying, trolling, stashing, sexting or stalking, but a partial and unidirectional analysis between the variables inhibits the observation of bullying as an extensive system of economic differences, political, social, cultural or educational among the parties involved [4]. It is about the establishment of a diversified agenda in its composition and extension, as well as heterogeneous among its actors. Therefore, the analysis of the relationships between the indicators of Internet harassment opens the discussion around the construction of a common agenda for stakeholders in which the victim and perpetrator are passive and active, specifying their function from the environment and electronic resources with which they have more than a pathology related to the violent, situational or dispositional nature of the parties involved [5]

\section{Studies of Harassment Agenda}

The specification of the model is based on the assumptions of the Theory of Reasoned Action, the Theory of Planned Behavior, the Theory of Self-efficacy, the Theory of Technology Acceptance, the Theory of Electronic Consumption and the Theory of the Dissemination of Innovations according to which the perceptions of utility, ease, risk, control, efficiency and compatibility directly and indirectly determine the use of a technology or electronic device. $\mathrm{L}$ a relationship between perceptual factors and cyberbullying direct (hypothesis 1). Or indirect through the perception of effectiveness 
(hypothesis 2) and / or the perception of ease (hypothesis 3). Direct relationships are estimated by multiple regressions in which seven perceptual variables simultaneously affect cyberbullying. This is because it is considered that an interrelation between the perceptual variables would affect the predictive power of each one over cyberbullying [6]

The perception of control, as established by the Theory of Planned Behavior, is a factor that, when associated with the intensive use of a technology, mainly affects the planning of an information device [7]. However, being a general perception, as established by the Theory of Reasoned Action, its predictive power is reduced to its minimum expression since it requires its association with another perceptual factor such as efficiency or ease of use [8].

In this way, the perception of utility, according to the Theory of Acceptance of Technology, influences to a greater extent if it is linked to the perception of ease of use, but it diminishes its impact if it is related to the perception of risk according to the Theory. of Electronic Consumption. This logic applies to each of the perceptual variables and their probable link between them when anticipating the effects of cyberbullying [9]. For its part, the perception of compatibility is more influential on the use of technology as predicated by the Theory of the Diffusion of Innovations since the relationship with another perception would be a difficult system to get along with lifestyle and intensive use of technology [10].

In the case of risk perception, the Theory of Electronic Consumption indicates that its power is more incisive on the use of an electronic device if the uncertainty or mistrust is not reduced by a perceptual factor of control or utility [11]. Finally, in the case of the perception of efficiency, the Theory of Self-efficacy warns that it has a greater impact on the use of technology if it is associated with the achievement of achievements which is very close to the perception of utility. That is why the indirect effect of perceived efficiency will be greater than its direct bearing on the use of technology [12].

In indirect relationships, the effects of perceptual variables obey the same logic of interrelation and determination, but unlike direct relationships, measurement errors have an influence on the estimation of an exogenous variable on an endogenous variable or mediator before predict the effects of their association on cyberbullying [13]

Both systems, direct routes and indirect pathways, to be included in the specification model try to predict the cyberbullyng considering different edges of interrelation between perceptual variables that the state of knowledge warns as fundamental but have only been able to establish by routes direct their predictive power.

Interrelationship between perceived usefulness, compatibility, control, harassment and impact risk by perceptions of effectiveness and ease, to cyberbullying shall conform to the observed data.

\section{Method}

A documentary study was carried out with sources indexed to international repositories such as Dialnet, Latindex, Publindex, Redalyc and Scielo, considering the period from 2010 to 2018, as well as the inclusion of key words. The information was processed based on the Delphi technique, which considers rounds of synthesis, qualification, discussion and integration of the differences between expert judges of the topics with the purpose of structuring criteria for the interpretation of an expert agenda that is compared with the agenda extracted from the literature review [14].

The synthesis of the data to be discussed in the first round was obtained from the literature review, highlighting the indicators: stalking, trolling, stashing, sextint and bullying, but without including reasoning about the relationships in order that the judges will evaluate the content, assigned -1 for content unfavorable to bullying, 0 for unlinked content and +1 for favorable content. The data were processed in the analysis package for social sciences (SPSS for its acronym in English version 17), frequencies and $d$ were estimated and from them hypotheses were established to specify the model.

\section{Results}

The contribution of the present work to the state of the question lies in the specification of a model in which two agendas were compared, one of experts who warn asymmetric relationships between the parties involved in the harassment but disconnected from the literature consulted which highlights the prevalence of lifestyles prone to risk and because of harassment.

\section{Final considerations}

Harassment in times of discussion opens up regarding its measurement because, given the diversity of components, the weighting of its dimensions and indicators becomes more complex, and a balance between definitions and their features is essential [15].

In the present work it has been argued that pre-existing differences between the actors involved such as the perpetrators, the victims, the spectators and the promoters, although it is a reflection of their economic, political, social, cultural or educational asymmetries, is also the establishment of an agenda that has focused its attention on axes and topics of discussion such as the harassment seen from pathologies that emerge in the interrelation. [16] warns that harassment is collateral and simultaneous to the use of the Internet itself, since the development of capacities, skills and information resources potentiates harassment not mediated by a technology, device or digital network.

Precisely, in this reflective line, this work highlights the relationships between the variables subtracted from a first review of the literature and specified in the qualification of expert judges. García, Hernández, Aguilar and [17] demonstrated that the 
intensive use of electronic devices and networks increases Internet user harassment in relation to other determinants that allude to expectations of achievement, identity, usefulness, ease and risk.

In effect, the situational factor combined with the dispositional factor, or, the intensive use of the internet added to the skills and knowledge explain the harassment, but only a type of harassment more oriented to the processing of information as a resource for the ridicule of a potential victim more than the observation of relationships between the interested parties, as is the case of those who search, store, document, process and disseminate information related to bullying [18-20]. The construction of an integral model is necessary in which, once the relationships between the variables are specified, it is possible to contrast the hypotheses in order to contribute to the state of the question.

\section{Conflict of interest}

No conflict of Interest.

\section{Acknowledgement}

None.

\section{References}

1. Romera E, Rey R, Ortega R (2011) Factors associated with the involvement in Bullying. A study in Nicaragua. Psychosocial Intervention 20: 61-70.

2. Garcia L, Orellana O, Pomalaya R, Yanac E, Sotelo L, et al. (2010) Cyberbullying in high school students in metropolitan Lima. Journal of Research in Psychology 13: 83-99.

3. Buelga S, Pons J (2012) Assault among teenagers through mobile phone and Internet. Psychological Intervention 21: 91-101.

4. Sago B (2013) Factors influencing social media adoption and frequency of use: And examination of Facebook, Twitter, Pirenterest and Google. International Journal of Business and Commerce 3: 1-14.

5. Valdés A, Yañez A, Martínez E (2013) Differences between subgroups of students involved in Bullying: victims, aggressors-victims and aggressors. Liberabit 19: 215-222.

6. Garaigordobil M, Oñederra J (2010) Emotional intelligence in the victims of bullying and in the aggressors. European Journal of Education Psychology 3: 243-256.
7. García L, Orellana O, Pomalaya R, Yanac E, Orellana D, et al. (2011) Intimidation among equals (Bullying): empathy and social maladjustment in Bullying participants. Journal of Research in Psychology 14: 271-276

8. Gómez A (2013) Bullying the power of violence. A qualitative perspective on bullies and victims in primary schools in Colima. Revista Mexicana de Investigación Educativa 18: 839-870.

9. Kotaman H (2010) Turkish early childhood educators' sense of teacher efficacy. Education \& Psychology 8: 516-603.

10. León B, Castaño E, Fajardo F, Gómez T (2012) Cyberbullying in a sample of high school students: modulating variables and social networks. Journal of Research in Educational Psychology 10: 771-778.

11. Martínez A, Reild L (2013) Psychometric validation of the "How we got in school" questionnaire to evaluate school bullying in the first few. Revista Mexicana de Investigación Educativa 18: 11-36.

12. Mendoza B (2011) Bullying between peers and the escalation of aggression in the student teacher relationship. Psychology Iberoamericana 19: 58-71.

13. Quintana A, Montgomery J, Malaver C, Ruíz G (2012) Perception of Bullying, conflict management and school climate in managers and teachers of educational centers. Journal of Research in Psychology 15: $35-47$.

14. Kupczynski L, Mundi M, Green M (2013) The prevalence of cyberbullying among ethnical groups of high school students. International Journal Educational Research 1: 48-53.

15. Molina HD, Llamas B, García C (2018) Reliability and validity of an instrument that measures perceived harassment on the Internet. Eureka, 15 (2): 225-243

16. García C (2018) Reliability and validity of an instrument that measures the use of the Internet. Context 7: 31-37.

17. García C, Hernández J, Aguilar JA, Morales ML (2017) Reliability and validity of an instrument that measures perceptual determinants of harassment through the Internet. Encounters 14 (1): 103-117

18. García C, Carreón J, Hernández J, Bustos J, Morales M, et al. (2013) Utilitarian and efficient dimensions of Internet use. Management Vision 12: 281-292.

19. Elizalde A (2010) Descriptive study of the coping strategies of Bullying, in Mexican teachers. Journal of research in Educational Psychology 8: 353-372.

20. León B, Castaño E, Gómez T, López V, López E (2011) Study of cyberbullying phenomenon in primary in the community of Extremadura. International Journal of Development and Educational Psychology 1: 553-560. 